\title{
Metaphysical Rationalism
}

\author{
Martin Lin
}

"To try and find out the reason for everything is very dangerous and leads to nothing but disappointment and dissatisfaction."

-Queen Victoria

The world, according to Spinoza, is an intelligible place. This conviction is reflected in his philosophy in numerous ways. He believes that the order of being and the order of reason mirror each other, as is evident in the way he defines his basic ontological categories both in terms of what inheres in what and what is conceived through what. Moreover, for him, every event is causally determined in accordance with natural laws that are always and everywhere the same. These laws follow from the eternal and infinite essence of God in the same way that the geometrical properties of a triangle follow from its nature. Thus, laws of nature are intelligible in the same way as the objects of geometry are intelligible, and all events conform to this rational order. Spinoza's confidence in the rationality of the world is also reflected in his Principle of Sufficient Reason, which says that if something exists, there is a cause or reason why it exists, and if it doesn't exist, there is an explanation of its nonexistence.

Not only does the world have an intelligible structure, but human reason is capable of discovering that structure. We have, in virtue of being modes of God, an adequate idea of the infinite and eternal divine essence that allows us to infer from it the laws of nature as well as the formal essences of singular things. Indeed, reason in the human mind is no different, for Spinoza, than reason in the divine intellect, and our ideas, insofar as they are rational, are indistinguishable from God's own. Reason, for Spinoza, is not only intellectually but morally important as well. Our highest good involves using reason to understand God or nature, ourselves, and our place in nature, which results in enduring happiness. 
Moreover, for him, the more rational we become the more powerful we are with respect to mastering ourselves and our environment and the more harmoniously we can live with our fellow human beings. Accordingly, many commentators have seen Spinoza's philosophy as a celebration of reason: its ability to penetrate the metaphysical structure of the world, to reveal the natural order, to bring happiness to the human mind and health to the human body.

We could call this conviction in the rational order of existence Spinoza's rationalism. This rationalism, in my view, is a heterogeneous phenomenon. It is a diverse collection of independent doctrines, each one of which expresses a general optimism about reason but none of which are entailed by this optimism. Some commentators, however, have sought to understand Spinoza's rationalism as a more systematic position that can be traced back to a single principle. For example, Michael Della Rocca writes:

Spinoza can be seen as a pure philosopher, always seeking explanation, always refusing to be satisfied with primitive, inexplicable notions. This purity is most evident in his commitment to the principle that each fact has an explanation, that for each thing that exists there is an explanation that suffices for one to see why that thing exists. [...] [T] his principle is known as the Principle of Sufficient Reason (PSR). [...] Spinoza employs the PSR more systematically, perhaps, than has ever been done in the history of philosophy. ${ }^{1}$

To be sure, Spinoza is a pure philosopher who seeks explanations and rejects mysteries and irrational superstition. I have no quarrel with understanding Spinoza in this way. And there can also be no doubt that Spinoza accepts a version of the Principle of Sufficient Reason. Nevertheless, I will argue here that recent commentators such as Della Rocca (and myself in earlier work) have misunderstood Spinoza's Principle of Sufficient Reason and its role in his system. Spinoza does not regard it as demanding an explanation of every fact but only of facts regarding existence and nonexistence. And, with the exception of the necessary existence of God, Spinoza does not derive any other important doctrines in the Ethics by applying the Principle of Sufficient Reason. Moreover, I will consider a number of cases in which commentators have argued that Spinoza could have derived or perhaps did in fact derive, albeit implicitly, doctrines by applying the Principle of Sufficient Reason. I will argue that, in each of these cases, Spinoza did not and indeed could not derive them from his version of that principle. In many cases, I will take Della Rocca's interpretation of Spinoza as my target. Della Rocca has done more than any other commentator to work out the implications of interpreting the Principle of Sufficient Reason as the engine 
behind Spinoza's philosophy. Because of the great ingenuity, philosophical acumen, and wit with which Della Rocca develops his interpretation, I think it is very well worthwhile to engage with it in detail, even if, in the end, I think that it is deeply mistaken.

\section{Spinoza's Principle of Sufficient Reason}

In the course of arguing for the necessary existence of God in E1p11d2, Spinoza claims that there is a cause or reason for the existence of everything that exists as well as a cause or reason for the nonexistence of everything that does not exist. Although Spinoza himself doesn't use the term, I think that we can fairly call this a Principle of Sufficient Reason. It demands a sufficient reason for a broad topic-neutral domain: facts about existence and nonexistence (existential facts hereafter). And Spinoza believes that we can learn an important truth by applying it: that God necessarily exists. These two features alone justify calling it a Principle of Sufficient Reason. But we should take care not to confuse Spinoza's Principle of Sufficient Reason with similar principles held by other philosophers. In particular, we should take care not to confuse Spinoza's Principle of Sufficient Reason with that of Leibniz, the philosopher who introduces the term into philosophical discussion and who is perhaps most associated with it. For Leibniz, the Principle of Sufficient Reason is not restricted to existential facts. Rather every truth, every fact, and every event has a sufficient cause or reason. ${ }^{2}$ What is more, Leibniz boldly declares that it is one of two great principles of all our reasoning, the other being the Principle of Contradiction, and he attempts to solve a wide variety of philosophical problems by deploying it. Spinoza, on the other hand, tucks his Principle of Sufficient Reason away in an alternative demonstration to E1p11, using it only once, to prove the necessary existence of God, never to mention it again. This in itself does not establish that it does not play an important but implicit role in his thinking, but it does shift the burden of proof onto those who wish to argue that it is at work throughout Spinoza's philosophy. Suffice it to say for now that Spinoza presents his Principle of Sufficient Reason very differently and much more modestly than, for example, Leibniz does. Later we will consider more closely the possibility that it plays a greater role behind the scenes.

First, however, we must clarify what Spinoza's Principle of Sufficient Reason says. What is its scope? What is a cause or reason? It might appear that the principle applies to substances and modes because those are the things the 
existence of which requires explanation. But this cannot be right because the principle applies to the non-existence of substances and modes as well. In the case of nonexistence, there are no substances or modes to receive a cause or reason. What then has a cause or reason in cases of nonexistence? Presumably, it is the fact that the substance or mode does exist. And this account smoothly extends to the case of existence as well. If a substance or mode exists, then there is a cause or reason for the fact of its existence. (Beware. There is no reason, at least at this point, to reify these facts. If you like, think of causes or because as sentential operators and not two-place predicates.)

Some commentators have alleged that Spinoza's Principle of Sufficient Reason is unusually strong because it applies not just to facts about existence but also to facts about nonexistence. ${ }^{3}$ This is misleading. Leibniz, for example, thinks that all facts require a cause or reason. ${ }^{4}$ This entails that facts about nonexistence require a cause or reason. Therefore, Leibniz's Principle of Sufficient Reason is stronger than Spinoza's because while Leibniz's entails Spinoza's, the converse does not hold. Moreover, there are many facts that do not pertain to existence or nonexistence, and Leibniz's Principle of Sufficient Reason requires these facts to have a cause or reason but Spinoza's does not. Furthermore, every universal generalization being logically equivalent to a negative existential (i.e., that all ravens are black is logically equivalent to the claim that there does not exist a nonblack raven), any Principle of Sufficient Reason that applies to universal generalizations ipso facto applies to negative existentials as well. Thus, Spinoza's Principle of Sufficient Reason could only be stronger than a Principle of Sufficient Reason that did not apply to universal generalizations, which would be a very weak Principle of Sufficient Reason indeed.

Many recent commentators have thought that, contrary to what I have just said, Spinoza's Principle of Sufficient Reason extends not just to facts about existence and nonexistence but to all facts. ${ }^{5}$ Indeed, although I now reject it, I myself have previously defended such an interpretation. Although this appears to outrun Spinoza's text by a wide margin, there is an apparently cogent argument to the effect that if the Principle of Sufficient Reason applies to all existential facts, then it applies to all facts without restriction. ${ }^{6}$ The argument for this flawed conclusion proceeds as follows. Modes are substances insofar as they satisfy some condition. Any condition satisfied by a substance grounds the existence of some mode. The existence of a mode requires a cause or reason. Thus, for facts about a substance's existence (i.e., for facts about a substance satisfying some condition) there is a cause or reason. But every fact entails the existence of a mode. This is because for any fact we can abstract a condition from it by means 
of the being such device. The claim that mastodons are bigger than dodo birds does not appear to be a claim about the existence or nonexistence of things. (It is not, for example, equivalent to the statement that there does not exist a mastodon that is not bigger than a dodo. Even if there were a dwarf-mastodon that was smaller than a dodo or if mastodon-fetuses were smaller than fullgrown dodos, it would still be true that mastodons are bigger than dodos.) But nonetheless we can abstract a condition from it that is satisfied by God: being such that mastodons are bigger than dodo birds. Because every condition that God satisfies determines a mode to exist, this fact is determined by something that requires a cause or reason. The fact that mastodons are bigger than dodos is nothing over and above the mode that exists in virtue of God being such that mastodons are bigger than dodos. For this reason, if the existence of every mode requires a cause or reason then every fact requires a cause or reason.

This argument rests on the false assumption that every condition satisfied by a substance determines the existence of a mode. Every condition cannot be a modemaker. This is because conditions are cheap and abundant and so do not obey the strictures placed on modes by Spinoza. For example, if every condition were a modemaker, then there would be modes that splayed across multiple attributes in an unacceptable way. For example, being such that a body exists and a mind exists is a condition satisfied by God. But if this condition were a modemaker, then there is a mode that is not fully conceivable under a single attribute. Every mode can be fully conceived under a single attribute and thus this condition cannot be a modemaker. There must be, therefore, a distinguished class of conditions that are modemakers. For example, it would be plausible to assume that, for Spinoza, the modemaking conditions are natural, attribute-bound, and non-relational. There must be other conditions as well. For example, God satisfies the condition is infinite but there is presumably no mode that is God insofar as he is infinite. If there were, would it be a mode of extension, a mode of thought, or a mode of some other attribute? None of these answers seem acceptable. But neither would it be acceptable to answer that it is a mode but not a mode of any attribute. Thus, the condition is infinite cannot be a modemaker. Spinoza is not explicit about how the modemaking conditions are restricted. I suspect, however, that the modemaking conditions for finite modes under the attribute of extension are those that result in the existence of bodies, and the modemaking conditions under the attribute of thought result in the existence of ideas that represent those bodies. The modemaking conditions for infinite modes will be those that result in the laws of nature and "the whole of nature" that has all finite modes as parts discussed in Lemma 7 of 
the Short Physical Digression following E2p13s. There are many truths that do not determine the existence of bodies, the ideas that represent them, the laws that govern them and those ideas, and the whole that those bodies and ideas compose. Thus, there are many truths that are not within the scope of Spinoza's Principle of Sufficient Reason.

Before looking at alleged uses of Spinoza's Principle of Sufficient Reason, let us first consider a useful distinction made by Leibniz between different ways that a class of truths can relate to it. ${ }^{7}$ First of all, the Principle of Sufficient Reason can apply to a certain class of truths. These are the truths that instantiate the principle. Leibniz, for example, holds that the Principle of Sufficient Reason applies to every truth, and Spinoza thinks that it applies to existential truths. These are the truths that have a sufficient reason. Second, the Principle of Sufficient Reason can ground a class of truths. For example, for Leibniz, all contingent truths are grounded by the Principle of Sufficient Reason in the sense that they are true because the Principle of Sufficient Reason is true. ${ }^{8}$ Although, for him, necessary truths have a sufficient reason, they are not grounded by it. Thus, the class of truths that are grounded by the Principle of Sufficient Reason is, for Leibniz, a subset of the class of truths to which it applies. Spinoza never explicitly tells us that any truth is true in virtue of the truth of the Principle of Sufficient Reason. The one truth to which he explicitly applies it, the existence of God, is a case of a truth that does not depend upon the truth of the Principle of Sufficient Reason. God, Spinoza tells us, is self-caused. That is to say, he exists entirely in virtue of his nature or essence. Assuming that the Principle of Sufficient Reason is not part of God's nature, his existence does not depend on it. Third, there are truths that can be learned by applying the Principle of Sufficient Reason. ${ }^{9}$ Leibniz, for example, thought that we could prove the existence of God, the Principle of Identity of Indiscernibles, the relationality of space, and the nonexistence of atoms by applying the Principle of Sufficient Reason. (It is worth noting that some of the truths that we can learn from the Principle of Sufficient Reason, according to Leibniz, do not depend upon it. For example, the necessary existence of God can be learned by applying the Principle of Sufficient Reason but it is a necessary truth and hence, for Leibniz, it depends not on the Principle of Sufficient Reason but on the Principle of Contradiction.) Spinoza only ever explicitly tries to derive the necessary existence of God from the Principle of Sufficient Reason but some commentators, most notably Della Rocca, have argued that Spinoza arrives at many other elements of his system by applying the Principle of Sufficient Reason, albeit "off-stage" as it were. We will consider some of those claims in this chapter with an eye toward determining the extent 
to which the Principle of Sufficient Reason plays role in Spinoza's system beyond what is manifest in his official demonstrations.

I think it's fair to say that of the three relations that the Principle of Sufficient Reason can bear to a class of truths-applying to, grounding, and allowing us to discover-the latter two are, in many respects, more interesting and important than the first. So long as a philosopher admits that anything has an explanation, she will accept that the Principle of Sufficient Reason applies to some truths so long as that principle is understood in a suitably restricted way. Thus, merely thinking that everything (suitably restricted) has an explanation is not enough to make a philosopher an adherent of the Principle of Sufficient Reason in any interesting sense. The more permissive or topic-neutral the restriction, however, the more such a principle looks like something deserving to be called a Principle of Sufficient Reason. But such a principle becomes even more philosophically significant if it can be used as an instrument of discovery or if it grounds certain truths. As we have seen, Spinoza's Principle of Sufficient Reason is restricted in a topic-neutral way. It applies to existential truths. In what follows, we will look to see what philosophical doctrines can be learned by applying it and if Spinoza thinks that any philosophically interesting truths are grounded by it.

\section{Necessitarianism}

Philosophers have often thought that commitment to the Principle of Sufficient Reason leads to necessitarianism, the doctrine that every truth is necessarily true, ${ }^{10}$ and most commentators believe that Spinoza is both committed to the Principle of Sufficient Reason and a necessitarian. ${ }^{11}$ Is he motived to be one by his commitment to the Principle of Sufficient Reason?

It is worth noting that Spinoza's explicit statement of necessitarianism is more restricted than is usually supposed. For example, it is often alleged that Spinoza believes that every truth is necessary. ${ }^{12}$ In fact, the only things that E1p29 says are necessary are the existence of modes and their actions. E1p33 also states that the order and connection of things is necessary. Thus, it appears that, in those texts, he commits himself only to the necessity of the following classes of truths: (1) existential truths; (2) causal truths; and (3) what we might call "structural truths," that is, truths about the order and connection of things. To be sure, Spinoza may believe or have reason to believe that other truths are necessary as well but those truths are not the subject of E1p29 and E1p33, and we cannot 
assume without argument that his conclusions there generalize further. I cannot pursue this issue further here and will leave it as an open question.

Why does Spinoza believe that existential, causal, and structural truths are necessary and does the Principle of Sufficient Reason play any role in his thinking? Let us look more closely at E1p29 and its demonstration, which read:

In nature there is nothing contingent, but all things have been determined from the necessity of the divine nature to exist and produce an effect in a certain way. [E1p29]

Whatever is, is in God (by E1p15); but God cannot be called a contingent thing. For (by E1p11) he exists necessarily, not contingently. Next, the modes of the divine nature have also followed from it necessarily and not contingently (by E1p16) - either insofar as the divine nature is considered absolutely (by E1p21) or insofar as it is considered to be determined to act in a certain way (by E1p28). Further, God is the cause of these modes not only insofar as they simply exist (by E1p24c), but also (by E1p26) insofar as they are considered to be determined to produce an effect. For if they have not been determined by God, then (by E1p26) it is impossible, not contingent, that they should determine themselves. Conversely (by E1p27) if they have been determined by God, it is not contingent, but impossible, that they should render themselves undetermined. So all things have been determined from the necessity of the divine nature, not only to exist, but to exist in a certain way, and to produce effects in a certain way. There is nothing contingent, q.e.d. [E1p29d]

This argument for necessitarianism with respect to existential and causal truths $(\mathrm{ECN})$ can be summarized as follows:

(1) Everything is either God or a mode of God. (E1p15)

(2) The existence of God is necessary. (E1p11)

(3) The existence of the modes is necessitated by the existence of God. (E1p16)

(4) Whatever follows from something necessary is itself necessary. (suppressed premise)

(5) The existence of the modes is necessary. (From 3 and 4)

(6) Causal relations between the modes are necessitated by the existence of God. (E1p26)

(7) Causal relations between the modes are necessary. (From 4 and 5)

(8) No substance or mode exists contingently and no casual relation obtains between contingently. (From 1, 2, 5, and 7)

The Principle of Sufficient Reason is not a premise of this argument and so it appears that Spinoza does not arrive at his necessitarianism by means of it. Of course, the Principle of Sufficient Reason is a premise of Spinoza's argument for 
the necessary existence of God, premise (2). But the necessary existence of God alone does not establish that every existential and causal truth is necessary. Many theists coherently believe that God exists necessarily but that not everything else exists and acts necessarily. Thus, although it is true that the argument for necessitarianism with respect to existential and causal truths depends on the Principle of Sufficient Reason to the extent that Spinoza's argument for the necessary existence of God depends upon the Principle of Sufficient Reason, the claim that Spinoza's necessitarianism depends on the Principle of Sufficient Reason suggests a much more extensive connection than that.

Apart from their connection to the necessary existence of God, do any of the other premises of the argument for necessitarianism with respect to existential and causal truths rely on or entail the Principle of Sufficient Reason? The first premise, everything is either God or a mode of God, follows from the fact that everything is either a substance or a mode and that there is only one substance, namely, God. Spinoza's argument for substance monism does not rely upon the Principle of Sufficient Reason. Rather, it depends on the assumption that there cannot be more than one substance with a given attribute. Although some commentators, including Della Rocca, ${ }^{13}$ have seen this premise as deriving from the Principle of Sufficient Reason via the Principle of Identity of Indiscernibles, it does not, as I will argue later in this paper. Does the claim that everything is a substance or a mode entail the Principle of Sufficient Reason? It might be argued that it does by claiming that conceiving implies explaining (CIE):

(1) A substance is conceived through itself. (E1d3)

(2) A mode is conceived through the substance in which it inheres. (E1d5)

(3) Everything is a substance or a mode. (E1p4d)

(4) Everything is conceived through something. (From 1, 2, and 3)

(5) For all $x$ and all $y$, if $x$ is conceived through $y$, then $x$ is explained by $y$.

(6) Therefore, everything is explained by something. (From 4 and 5)

Despite first impressions, the conclusion (6) is not Spinoza's Principle of Sufficient Reason nor does the Principle of Sufficient Reason entail it. This is because Spinoza's Principle of Sufficient Reason requires explanations for facts about nonexistence, which are neither substances nor modes, and thus fall outside of the domain of Spinoza's quantifiers. For this reason, the conclusion (6) could be true even if Spinoza's Principle of Sufficient Reason is false. ${ }^{14}$ Nevertheless, it does establish the positive part of the Principle of Sufficient Reason and thus could be viewed as partial support of it. For this reason, it is worth asking whether or not it is a genuinely Spinozistic argument. 
The credentials of premises 1-4 above are beyond dispute, but what about premise 5? Della Rocca has argued that a number of texts seem to imply that if $x$ is conceived through $y$, then $x$ is understood through $y .{ }^{15}$ If we also assumed that if $x$ is understood through $y$, then $y$ explains $x$, we would have (5): For all $x$ and all $y$, if $x$ is conceived through $y$, then $x$ is explained by $y$. The relevant texts do not, however, strongly support Della Rocca's contention.

The first text called upon by Della Rocca is E1a5, which says:

Things that have nothing in common with one another also cannot be understood [intelligi] through one another, or the concept of the one does not involve the concept of the other. [E1a5]

In this text, Spinoza appears to equate understanding one thing through another with conceiving one thing through another. If we assume that understanding is the state produced by successful explanation, then we might think that Spinoza is equating conceiving one thing through another with explaining one thing through another.

But the Latin word intelligere, like the English understand, can be used to express meanings that have no connection to explanation. For example, it can mean "to grasp," as in grasping a meaning or a concept. According to this usage, if I say that bachelorhood is partially understood (i.e., intelligi) through being unmarried, that is to say, the concept of bachelorhood involves the concept of being unmarried, I am not asserting any equivalence between $x$ is conceived through and $x$ is explained by. I am merely asserting that the concept of a bachelor involves the concept of being unmarried. Likewise, a natural interpretation of 1a5 is that one thing can be grasped in thought by grasping something else in thought only if the concept of the one involves the concept of the other. Thus, this text does not appear to offer much evidence in favor of premise (5) of the claim that conceiving implies explaining.

Another piece of putative evidence for premise (5) is that Spinoza sometimes says that substances are conceived under an attribute, and in other texts Spinoza says that substances are explained by their attributes. Della Rocca alleges this is because being conceived by and being explained by [explicatur] are the same relation. ${ }^{16}$ But this inference is hasty. First of all, it would not be particularly surprising if substance and its attributes simply stood in more than one relation. Moreover, it is not clear that explicatur means is explained by in this context. It can also be translated as is conveyed by, is exhibited by, and is expressed by. I argue elsewhere that the attributes are the essence of a substance, which is conceived under various guises. ${ }^{17}$ But Spinoza, like many seventeenth-century 
philosophers, isn't always careful about distinguishing a thing from the concept of that thing. Consequently, he doesn't always clearly distinguish the essence, which is conceived under a guise, and the guise under which it is conceived. I am inclined, therefore, to think that when Spinoza says that substance is both conceived under and exhibited by the attributes, he means that our cognitive grasp of substance is mediated by the guise by means of which it is presented to our intellect. But this does not imply that to conceive of something is to have an explanation of it in the sense of knowing its cause or reason. Therefore, these texts do not provide evidence in favor of premise (5): for all $x$ and all $y$, if $x$ is conceived through $y$, then $x$ is explained by $y$.

Della Rocca also cites E2p7s, where Spinoza writes:

The formal being of the idea of the circle can be perceived [percipi] only through another mode of thinking, as its proximate cause, and that mode again through another, and so on, to infinity. [E2p7s]

Why does Spinoza say that we can "perceive" something only through a cause? A possible answer is that perceives means conceives and conceives means explains. Then Spinoza would just be saying that we can explain something only through a cause, which is a sensible doctrine. But that conceives means explains is an unnecessary hypothesis in this context. In Latin, percipere can mean to understand. Thus, in this text, Spinoza simply means that things are understood through their causes. Della Rocca points out that Spinoza sometimes uses percipere and concipere interchangeably (e.g., E2p38d or E2p49s). But this shows very little because percipere is a word with several meanings including both to understand and to conceive. What remains to be shown is that Spinoza is using it to express the same meaning in both contexts and there is no evidence from E2p7s or elsewhere that this is the case. I conclude that the textual basis for attributing to Spinoza premise (5) of the claim that conceiving implies explaining is slight.

Let us now consider premise (3) of the argument for necessitarianism with respect to existential and causal truths, which says that the modes are necessitated by the necessary existence of God. Does it rest upon the Principle of Sufficient Reason? Spinoza argues for this claim in the demonstration to 1p16 where he attempts to show that the world is produced by God. He argues for this by saying that God is infinitely real and the more reality a thing has, the more things follow from its essence. Therefore, infinitely many things follow from God's essence. What Spinoza means by these dark sayings is far from clear but Della Rocca thinks that Spinoza is committed to the claim that God is 
infinitely real by his commitment to the Principle of Sufficient Reason. ${ }^{18}$ (Della Rocca's statement of the argument relates somewhat loosely to the text so, in what follows, I have adapted his formulation to bring it closer to the letter of E1p16d.) Spinoza, Della Rocca notes, equates reality with power. If there were a possible mode that did not follow from God's nature, then there must be, by the Principle of Sufficient Reason, a cause or reason for the fact that it doesn't. There is no other substance that could prevent it following from God's nature and no mere mode could prevent it. There is, therefore, no possible explanation for this lack and thus it is impossible. Della Rocca concludes that every possible mode follows from God's nature, that is, God has the greatest possible degree of reality.

Della Rocca's argument is not Spinozistic because it assumes that there must be a cause or reason for facts of the form substance $S$ does not have power $P$. This is not an existential truth and so Spinoza's Principle of Sufficient Reason does not require a cause or reason for it.

Indeed, it is open to doubt that any sensible Principle of Sufficient Reason could demand an explanation of such truths. To see this, suppose that God lacked the power to cause some possible mode $m$. If God lacked this power, then his essence would not necessitate $m$. But because God's essence and power are one and the same, God lacking a power that he actually has is the same thing as having a different essence than he actually has. Thus, saying that if God lacked a power there would have to be an explanation of this lack is the same as saying that if God had a different essence there would have to be an explanation of this fact. But if it were legitimate to demand an explanation why God has the essence he would have if his essence were different, then it would be legitimate to demand an explanation of the fact that God has the essence that he actually does. To ask why something has the essence that it does is thus tantamount to asking why something is what it is. Consider the essentialist truth that gold atoms are gold atoms in virtue of having atomic number 79. This fact explains why atoms with atomic number 79 are gold atoms. But suppose someone wanted an explanation of this truth and asked, why are gold atoms what they are in virtue of having atomic number 79 ? There is no explanation of this fact. Having atomic number 79 is just what it is to be a gold atom. Similarly, there is no explanation of the fact that God has the powers that he does. Having such power is just what it is to be God. ${ }^{19}$

Let us now consider premise (6) of the argument for necessitarianism with respect to existential and causal truths, which says that the causal relations in which the modes stand follow from the divine nature. Why does Spinoza believe this? In causing the existence of the modes, God ipso facto realizes their essences 
because, as previously mentioned, the realization of an essence is the satisfaction of the necessary and sufficient conditions for the existence of a thing. ${ }^{20}$ The essence of a thing determines its causal powers, which in turn determines a thing's actions and its role in the natural order. ${ }^{21}$ The causal powers of a thing determine its actions because Spinoza defines action in terms of causation. Insofar as a thing produces an effect in virtue of its essence alone, it acts. ${ }^{22}$ In contrast, passions are changes in a mode's state that are determined by its own essence under the influence of external causes. ${ }^{23}$ These external causes act on the modes in virtue of their essences. Thus, the behavior of one who suffers passions is determined by its essence and the essence of external causes. ${ }^{24}$ Note that both actions and passions are fully determined by the essences of things taken together. Jointly the actions and passions of all the modes constitute the order and connection of nature. Thus, in explaining the existence of the modes, God thereby also explains the actions of the modes and the causal order that they manifest. And yet, premise (6) does not follow from Spinoza's Principle of Sufficient Reason. Rather it is dictated by Spinoza's conception of causation, the relationship between God and his modes, and the relationship between existence and essence. He argues for it in E1p26 and E1p26d, where he says:

A thing which has been determined to produce an effect has necessarily been determined in this way by God. [E1p26]

That through which things are said to be determined to produce an effect must be something positive (as is known through itself). And so, God, from the necessity of his nature, is the efficient cause both of its essence and of its existence (by E1p25 and E1p16). [E1p26d]

Spinoza's reasoning for this argument can be paraphrased thus:

(1) A mode is determined to produce an effect through something positive.

(2) The only positive things that could determine a mode to produce an effect are the existence and the essence of the mode.

(3) God determines both the existence and the essence of things. (E1p16 and E1p25)

(4) If $x$ determines $y$ and $y$ determines $z$, then $x$ determines $z$.

(5) Therefore, a mode is determined to produce an effect by God.

This argument does not have Spinoza's Principle of Sufficient Reason as a premise. Does Spinoza arrive at any of them by applying the Principle of Sufficient Reason? It would appear not. Spinoza says premise (1) is known through itself. Premise (2) is a suppressed premise, the falsity of which appears 
compatible with Spinoza's Principle of Sufficient Reason. Premise (3) derives from E1p16, which we have seen does not rely on the Principle of Sufficient Reason and E1p25, which is a direct consequence of E1p16. The falsity of premise (4) also appears compatible with the truth of the Principle of Sufficient Reason because it is coherent to think that every existential fact has an explanation but that explanation is not transitive. Consequently, premise (6) of the argument for necessitarianism with respect to existential and causal truths is neither learned through nor grounded by the Principle of Sufficient Reason.

We must conclude that Spinoza's argument for necessitarianism does not depend on his Principle of Sufficient Reason beyond the role it plays in establishing premise (3), the necessary existence of God. It is worth considering, nevertheless, whether Spinoza's Principle of Sufficient Reason might commit him to necessitarianism for other reasons. Consider the following well-known argument for necessitarianism from the Principle of Sufficient Reason ${ }^{25}$ :

(1) There are contingent truths. (Assumption for reductio)

(2) There is a cause or reason for every truth. (The Principle of Sufficient Reason)

(3) $p$, the conjunction of every contingent truth, is contingent.

(4) There is a cause or reason for $p$. (From 2)

(5) The cause or reason of $p$ is either a truth that is either contingent or necessary.

(6) If it is contingent, then some contingent truth explains itself.

(7) No contingent truth explains itself.

(8) If it is necessary, then $p$ is necessary.

(9) Therefore, there are no contingent truths.

Notice that if we substitute Spinoza's Principle of Sufficient Reason, that there is a cause or reason for every existential truth, for (2), we will not be able to derive the conclusion. This is because not every contingent truth is existential (e.g., mastodons are bigger than dodos) and so the conjunction of every contingent truth is not existential. Consequently, Spinoza's Principle of Sufficient Reason does not tell us whether or not $p$ has an explanation.

\section{The Identification of Existence and Conceivability}

Spinoza thinks that something exists if and only if it is conceivable. ${ }^{26}$ Della Rocca has argued that we can understand Spinoza's commitment to the equivalence of 
existence and conceivability as stemming from two commitments, both of which derive from the Principle of Sufficient Reason. ${ }^{27}$ One is that existence cannot be brute and primitive and must instead be explained in terms of something else. Fortunately, according to Della Rocca, Spinoza can explain existence in terms of conceivability. The other is that existence is identical to conceivability. It is not clear that these two claims are consistent: if existence is identical to conceivability and is explained by conceivability, then existence is explained in terms of existence, which Della Rocca explicitly denies when he says that, for Spinoza, existence must be explained in terms of something else. I am not sure how to resolve this tension, and so I will focus on each of these claims separately, beginning with the claim of identity.

Della Rocca begins by noting that in E1p20, Spinoza says that the same attributes that explain God's essence also explain his existence and therefore his essence and existence are one and the same. Della Rocca discerns in this inference the following principle:

- If there is no difference in the things that $a$ and $b$ are explained by, then $a$ and $b$ are identical. ${ }^{28}$

He thinks that this principle follows from the Principle of Sufficient Reason because nonidentity would be brute if two things were different despite being explained by all the same things. God's essence is given by his definition, which says that he is an absolutely infinite substance. Substances in turn are defined as things that are conceived through themselves. God's essence, Della Rocca concludes, is his conceivability. Thus, God's essence is identical to his conceivability. God's essence is identical to his existence. Thus, God's existence is identical to his conceivability. Next Della Rocca argues that the existence of modes too is identical to conceivability. If, in the case of modes, existence and conceivability are different, then, by the Principle of Sufficient Reason, it cannot be a brute fact that they are different. But their existence and conceivability are necessarily coextensive. Della Rocca asserts that given their necessary coextensiveness, nothing could explain their difference. Therefore, Spinoza is under pressure from the Principle of Sufficient Reason to identify them.

But the identification of existence and conceivability would make it possible to infer, from certain Spinozistic doctrines, claims that Spinoza would reject. For example, in E1d1, Spinoza says:

By cause of itself I understand that whose essence involves existence, or [sive] that whose nature cannot be conceived except as existing. [E1d1] 
If Della Rocca is correct and existence and conceivability are identical, then we ought to be able to paraphrase E1d1 by substituting "conceivable" for "existing":

By cause of itself I understand that whose essence involves existence, or [sive] that whose nature cannot be conceived except as conceivable.

The resulting paraphrase defines self-causation as having an essence that must be conceived as conceivable. Thus, anything that is not self-caused must have an essence that can be conceived of as inconceivable. Any actually existing mode has an essence that is conceivable, but do any of them have essences that can be conceived of as inconceivable? What would it mean to conceive of a conceivable essence as inconceivable? To conceive of something $x$ that is actually $F$ being not-F is to conceive of $x$ as not-F. The problem here is not the Berkeleian point that if $F$ denotes being conceivable, we cannot conceive of it as unconceived because we are conceiving of it. The Berkeleian point is a mistake that results from confusing properties of the representation with represented properties. Rather, the problem is that finite modes are not conceived through their essence alone but through their essence in conjunction with the substance in which they inhere. And so, to conceive of the essence of a mode as inconceivable would be to conceive of something that is either actually self-consistent as possibly inconsistent or actually consistent with the divine essence as inconsistent with the divine essence. Both are impossible because essences are such that they are self-consistent or consistent with another necessarily. We are thus forced to conclude that every conceivable thing is self-caused. But Socrates is conceivable, and so Socrates must be self-caused. This consequence is unacceptable to Spinoza because he thinks that no finite mode is self-caused. Given this, Spinoza must acknowledge a distinction between conceivability and existence on pain of contradiction.

What about Della Rocca's claim that the necessary coextensiveness of existence and conceivability puts pressure on Spinoza to identify them? Even if these relations were coextensive or even necessarily coextensive, I do not think that this would put pressure on Spinoza to conclude that they were identical. Della Rocca thinks that relations and properties that are necessarily coextensive are either the same or their difference is brute. Thus, he thinks that Spinoza must individuate relations and properties intensionally. But if Spinoza is a necessitarian (although I have only argued for a restricted necessitarianism here, I believe, as many commentators do, that Spinoza's necessitarianism is unrestricted), intensions collapse into extensions. An extensional principle of individuation for properties is exceedingly coarse-grained. Consider the properties of having 
a heart and having kidneys. These properties are coextensive because every creature with a heart also has kidneys and vice versa, and yet having a heart is manifestly not the same as having kidneys. Seeking greater fineness of grain, many philosophers appeal to intensional notions. An intension is a function from possible worlds to extension. Thus, while "having a heart" and "having kidneys" have the same extension, they have different intensions because there are possible creatures with hearts but not kidneys and vice versa. The way of intensions is not open to Spinoza because as a necessitarian there is only one possible world and so there is no difference between extension and intension. Unless Spinoza is stuck with such a coarse-grained conception of properties that he cannot tell the difference between having a heart and having kidneys, he will need hyperintensional notions, that is, notions that differ despite having the same intensions (and, a fortiori, the same extensions). Della Rocca assumes a difference in properties must either be explained by a difference in intension or be seen as brute and inexplicable, neglecting the possibility that the difference is explained by a difference in hyperintension.

Furthermore, the version of the Principle of Sufficient Reason that Della Rocca's argument requires rules out any brute facts, including brute facts about the identity and nonidentity of properties. Spinoza's Principle of Sufficient Reason, however, does not require explanations for facts about the identity and nonidentity of properties, only for facts about existence and nonexistence. As such, it does not put any pressure on him to identify necessarily co-extensive properties even granting that such an explanation would be impossible.

Let us now consider Della Rocca's claim that conceivability explains existence; things exist in virtue of being conceivable. I suppose that there is a sense in which this is true, but it also runs the risk of flattening the difference between what is self-caused and what is not. God's existence is fully explained by his essence. Thus, in a way, his existence is explained by his conceivability. What is the explanation of the existence of any mode? It is partially explained by the fact that it is conceivable and partially explained by the fact that God has infinite reality and thus every conceivable thing follows from his nature. It is true that, for an intellect that adequately grasps all things, the nonexistence of any actually existing mode would be inconceivable. But it wouldn't exist simply in virtue of being conceivable but rather being conceivable through a substance that is infinitely real. To be sure, such an absolutely real substance is the only conceivable substance and thus any conceivable mode is conceived through such a substance. Nevertheless, if someone were to ask why a given mode exists, and she was told it was because it was conceivable, she would not have the complete 
explanation unless she also was told that it is conceivable through a necessary being that has infinite reality. To the extent that this latter information is an indispensable part of the explanation, the existence of the modes is not fully explained in terms of mere conceivability.

\section{The Identity of Indiscernibles}

Some commentators have thought that Spinoza is motivated to accept his version of the Principle of Identity of Indiscernibles because he accepts the Principle of Sufficient Reason. ${ }^{29}$ In E1p5d, Spinoza says that "if there were two or more distinct substances, then they would have to be distinguished from one another either by a difference in their attributes or by a difference in their affections." Spinoza's reasons for believing this are unclear. He cites E1p4, which says that if two distinct substances are distinguished, then they are distinguished by a difference in attribute or mode. But that proposition makes only a conditional claim and does not say that distinct substances must be distinguished, which is required by the Principle of Identity of Indiscernibles. Neither does the demonstration of E1p4 offer any insight because it focuses exclusively on the question of what entities are available to distinguish different substances and does not address the question of whether or not different substances must be distinguished in the first place. ${ }^{30}$

Does Spinoza implicitly rely on more cogent reasoning to arrive at his Principle of Identity of Indiscernibles? It is tempting to think that the Principle of Sufficient Reason plays a role here because it is sometimes alleged that the Principle of Sufficient Reason entails the Principle of Identity of Indiscernibles and Spinoza undoubtedly accepts a version of the Principle of Sufficient Reason. How does the Principle of Sufficient Reason entail the Principle of Identity of Indiscernibles? Typically, something like the following argument is invoked. ${ }^{31}$ Call a truth an identity if it results from an object satisfying an identity predicate such as is identical to $B$ or is not identical to $B$. Call a truth a qualitative truth if it results from an object satisfying a purely qualitative predicate, which is a predicate that is not formed using any device of direct reference such as a proper name or a demonstrative. There is an explanation of every truth (i.e., the unrestricted Principle of Sufficient Reason). Therefore, there is an explanation for every identity. The only thing that can explain an identity is a qualitative truth. If qualitative truths explain identities, then, for any objects A and B, if A and B satisfy all the same qualitative predicates, then they satisfy all the 
same identity predicates. Suppose for reductio that there were two distinct yet indiscernible objects A and B. A and B satisfy all the same qualitative predicates because they are indiscernible. Thus, they satisfy all the same identity predicates. But this is contrary to the supposition that they are distinct. Therefore, there are no two distinct yet indiscernible objects.

But the version of the Principle of Sufficient Reason used in this argument is not Spinoza's. To see this, suppose there were two indiscernible yet numerically distinct substances A and B. It is true that A is not B and B is not A. Suppose further that there is no explanation why A is not B. Does this scenario violate Spinoza's Principle of Sufficient Reason? Spinoza's Principle of Sufficient Reason only requires an explanation of the existence of $A$ and the existence of $B$ and therefore it requires an explanation of the fact that $\mathrm{A}$ is not $\mathrm{B}$ only if this fact is identical to an existence fact. But this cannot be because identity is not existence. To see this, consider the fact that we cannot replace every sentential clause concerning identity with a clause concerning existence salva veritate. For example, we consider the following true statement: If the tallest man is six feet tall, then the youngest man is six feet tall because the tallest man is identical to the youngest man. There is no sentence that concerns existence alone that can replace the sentential clause following the "because" salva veritate. For example, even supposing the original sentence is true, the following is false: If the tallest man is six feet tall, then the youngest man is six feet tall because the tallest man exists and the youngest man exists.

Indeed, it is far from clear that any version of the Principle of Sufficient Reason entails the Principle of Identity of Indiscernibles. The argument for the Principle of Identity of Indiscernibles from the Principle of Sufficient Reason considered earlier must assume that identities are grounded by qualitative truths. Otherwise, the nonidentity of $\mathrm{A}$ and $\mathrm{B}$ could be explained by the fact that, necessarily, $\mathrm{A}$ is not $\mathrm{B}$ or that it is part of A's essence that $\mathrm{A}$ is not $\mathrm{B}$ or that it is a conceptual truth that A is not B. Or the A is not B in virtue of A's haecceity. Thus, identities could have explanations even if the Principle of Identity of Indiscernibles is false. Only when we make that further assumption that identity truths are grounded by qualitative truths do we get the Principle of Identity of Indiscernibles. But this assumption is sufficient all by itself to derive the Principle of Identity of Indiscernibles and indeed is logically equivalent to it. ${ }^{32}$ The Principle of Sufficient Reason is completely otiose in this argument.

Although it is a somewhat philosophically disappointing conclusion, the available evidence strongly suggests that Spinoza puts his Principle of Identity of Indiscernibles into his system by hand rather than deriving it from more 
basic principles. There is no textual evidence to support the contention that he derives it from his Principle of Sufficient Reason, and there are no philosophical considerations that would lead us to conclude that he should or could derive it from that principle.

\section{Conclusion}

For Spinoza, the world is an intelligible place. The existence and nonexistence of everything have a cause or reason. What is more, this cause or reason is sufficient for it. Given the cause or reason, it either must exist or couldn't exist. This is his Principle of Sufficient Reason. But there are other ways in which the world is intelligible as well. Everything has an essence that fully determines a complete set of intrinsic properties, causal powers, and actions. The interaction of the essences fully determines the complete set of passive affects or passions found throughout nature. These causal relations are subsumed under exceptionless laws. Moreover, these laws, essences, and intrinsic properties are knowable by us. The eternal and infinite essence of God is known to us in virtue of the fact that our natures are finite expressions of God's essence and thus we have an adequate idea of it. Every idea that follows from an adequate idea is itself adequate. The laws of nature are infinite modes and as such follow from the absolute nature of God. Thus, we can have an adequate idea of them. The essences of singular things also follow from the absolute nature of God and we so can know them too. Moreover, the intrinsic properties of things which are common to everything falling under the same attribute are equally in the part as in the whole and thus we can have adequate knowledge of them as well.

I have argued that there are many facts to which Spinoza's Principle of Sufficient Reason does not apply. Are these facts brute or unintelligible? For example, the fact that causation is distinct from conception is not within the scope of Spinoza's Principle of Sufficient Reason. Is it thereby unintelligible? I think not. Consider the properties of being triangular and being trilateral. They are, I would argue, distinct and yet necessarily coextensive. What if someone were to ask why they were distinct? What could we say to her to explain their distinctness? I can imagine no more effective procedure than trying to explain what a side is and what an angle is and then explaining being triangular and being trilateral in terms of them. At bottom, however, this procedure simply aims at giving her the concepts triangular and trilateral. Anyone who doubts that they are different simply doesn't possess the relevant concepts. (Or is biting a bullet.) 
The distinction isn't brute in the sense of being arbitrary or unintelligible. If it is correct to call it brute it is only because it is basic or fundamental. Similarly, consider someone who wants an explanation of why Socrates is Socrates. She does not wonder, for example, why the teacher of Plato is the husband of Xanthippe. Rather she wonders why that man (perhaps she is pointing at him from across the agora) is himself. What an odd question! But perhaps we could answer it by saying simply that everything is what it is and not another. And if an explanation were requested for this? I do not believe an explanation is possible but it nevertheless seems incorrect to say that this fact is arbitrary and unintelligible. It is, rather, basic and fundamental. Seeing that it must be so is a perquisite for thinking about anything at all. Thus, I do not think that facts such as the distinctness of causation, conception, and inherence or the distinction between the attributes are violations of the Principle of Sufficient Reason in the sense that they are arbitrary or unintelligible aspects of the world. Rather, they are not the sorts of things to which a Principle of Sufficient Reason ought to apply. Sometimes your spade is turned not because you've accidently hit an arbitrary or unintelligible stone but because you hit the bottom.

\section{Notes}

1 Michael Della Rocca, Spinoza (New York: Routledge, 2008), 30.

2 GP VI 612/L 646.

3 Della Rocca, Spinoza, 4; Yitzhak Y. Melamed, “The Sirens of Elea: Rationalism, Monism and Idealism in Spinoza," in Debates in Early Modern Philosophy, ed. Stewart Duncan and Antonia LoLordo (New York: Routledge, 2012), 78; Martin Lin “Rationalism and Necessitarianism," Noûs 46, no. 3 (2012): 418-448, here 420-421.

4 GP VI 612/L 646.

5 Don Garrett, “Spinoza’s ‘Ontological' Argument,” Philosophical Review 88, no. 2 (1979): 198-223, here 202, fn5; Della Rocca, Spinoza, 4; Martin Lin, "The Principle of Sufficient Reason in Spinoza," in The Oxford Handbook of Spinoza, ed. Michael Della Rocca (New York: Oxford University Press, 2017). NB. I have changed my mind about many things in this article.

6 Lin, "Rationalism and Necessitarianism": 420-421. See also Michael Della Rocca, "Interpreting Spinoza: The Real Is the Rational," Journal of the History of Philosophy 53, no. 3 (2015): 525-526.

7 See Robert Sleigh, "Leibniz on the Two Great Principles of All Our Reasoning," Midwest Studies in Philosophy 8, no. 1 (1982): 193-216, here 194-195. 
8 A VI.4.1616; GP VII 355-356/LC 15-16.

9 GP VII 355-356; LC L2; AG 321.

10 Jonathan Bennett, A Study of Spinoza's Ethics (Indianapolis, IN: Hackett, 1984), 115; Della Rocca, Spinoza, 77-78; Lin, “The Principle of Sufficient Reason in Spinoza," and Lin, "Rationalism and Necessitarianism," 420-421; Peter van Inwagen, Metaphysics, 4th edn. (Boulder: Westview Press, 2015), 150-153.

11 For an opposing view, see Edwin Curley, Spinoza's Metaphysics: An Essay in Interpretation (Cambridge: Harvard University Press, 1969), 106-109, and Edwin Curley and Gregory Walski, "Spinoza's Necessitarianism Reconsidered," in New Essays on the Rationalists, ed. Rocco J. Gennaro and Charles Huenemann (New York: Oxford University Press, 1998).

12 Della Rocca, Spinoza, 7; cf. Don Garrett, "Spinoza’s Necessitarianism," in God and Nature in Spinoza's Metaphysics, ed. Yirmiyahu Yovel (Leiden: Brill, 1991), 191-192.

13 Della Rocca, Spinoza, 47.

14 See John Morrison, "The Relation between Conception and Causation in Spinoza's Metaphysics," Philosopher's Imprint 13, no. 1 (2013): 1-17, here 3.

15 Michael Della Rocca, Representation and the Mind-Body Problem in Spinoza (New York: Oxford University Press, 1996), 3-4.

16 Ibid., 3.

17 Martin Lin, Being and Reason: An Essay on Spinoza's Metaphysics (New York: Oxford University Press, forthcoming), ch. 4.

18 Della Rocca, Spinoza, 77-78.

19 Cf. Daniel Garber, "Superheroes in the History of Philosophy: Spinoza, SuperRationalist," Journal of the History of Philosophy 53, no. 3 (2015): 507-521, here 518. Garber calls the fact that God has the essence that he does a brute fact, which violates the Principle of Sufficient Reason that Della Rocca attributes to him. In a sense, this is correct. Della Rocca does attribute such a Principle of Sufficient Reason to Spinoza, and there could be no explanation of the fact in question. Rather than call it a brute fact, I prefer to think of it as the kind of fundamental fact for which no sensible Principle of Sufficient Reason demands an explanation, what Shamik Dasgupta calls an "autonomous fact," in his "Metaphysical Rationalism," Noûs 50, no. 2 (2016): 379-418, here 383.

20 E2d2.

21 E1p36 and E1p36d.

22 E3d2.

23 Ibid.

24 E4p5 and E4p5d.

25 Bennett, Study, 115; Van Inwagen, Metaphysics, 150-153.

26 In E1p16 Spinoza says that everything that falls under an infinite intellect follows from the nature of God. An infinite intellect is unlimited (by E1d2) and 
thus can conceive of every conceivable thing. In other words, if something is conceivable, then it exists. E1a2 says that everything that is not conceived through itself is conceived through another. That something is conceived entails that it is conceivable. Thus, we can infer from E1a2 that if something exists, then it is conceivable. We can combine the conditionals derived from E1p16 and E1a2 into the following biconditional: something exists just in case it is conceivable.

27 Michael Della Rocca, “A Rationalist Manifesto," Philosophical Topics 31, no. 1 (2003): 75-93, here 82-88, and Della Rocca, Spinoza, 9.

28 Della Rocca, Spinoza, 262.

29 Ibid., 47; Yitzhak Melamed, Spinoza's Metaphysics: Substance and Thought (New York: Oxford University Press, 2013), xv.

30 Martial Gueroult asserts that E1p4 is equivalent to E1a1 in his Spinoza 1: Dieu (Paris: Aubier-Montaigne, 1968), 117. But E1al says what exists and not what serves to distinguish the distinct things that exist.

31 See Leibniz A 6.4.1645/AG 32.

32 See Gonzalo Rodriguez-Pereyra, Leibniz's Principle of Identity of Indiscernibles (Oxford: Oxford University Press, 2014), 59. 